\title{
Effects of stress ratio on crack growth rate and fatigue strength for high cycle and very-high-cycle fatigue of metallic materials
}

\author{
Chengqi Sun, Zhengqiang Lei, Youshi Hong* \\ State Key Laboratory of Nonlinear Mechanics, Institute of Mechanics, Chinese Academy of Sciences, Beijing 100190, China
}

\section{A R T I C L E I N F O}

\section{Article history:}

Received 27 June 2012

Received in revised form 25 June 2013

Available online 5 November 2013

\section{Keywords:}

Stress ratio

Crack growth rate

Fatigue strength

Very-high-cycle fatigue

Metallic materials

\begin{abstract}
A B S T R A C T
This paper studies the effects of stress ratio $R$ on crack growth rate and fatigue strength for high cycle and very-high-cycle fatigue of metallic materials. First, the effect of $R$ on fatigue crack growth rate is analyzed, and the result shows that the effect of $R$ on crack growth rate at near-threshold region and on Paris region is well expressed by a unified relation. Then, a model is developed for describing the fatigue crack growth rate with the effect of $R$ in nearthreshold region and Paris region. The model is verified by experimental data of metallic materials in literature. Finally, a formula is derived for the effect of $R$ on fatigue strength. The estimated results are in good agreement with the experimental data for high cycle and very-high-cycle fatigue regime in literature. The comparison of the present result with Goodman diagram is also discussed.
\end{abstract}

(c) 2013 Elsevier Ltd. All rights reserved.

\section{Introduction}

Since Paris and Erdogan (1963) proposed the wellknown crack growth relation, a number of models have been developed to describe fatigue crack growth rate $\mathrm{dal}$ $\mathrm{d} N$ for metallic materials (e.g. Elber, 1970; Huang and Moan, 2007; Jones et al., 2008; Ostash et al., 2011; Baptista et al., 2012; Kim et al., 2012; Xiong and Hu, 2012; Zambrano et al., 2012). Among these, Elber (1970) introduced the concept of crack closure and used the effective stress intensity factor range $\Delta K_{\text {eff }}$ instead of stress intensity factor range $\Delta K$ as the driving force for fatigue crack growth, namely $\mathrm{d} a / \mathrm{d} N=C\left(\Delta K_{\text {eff }}\right)^{m}$, where $\Delta K_{\text {eff }}=K_{\text {max }}-K_{\text {op }}$, with $K_{\text {max }}$ being the maximum stress intensity factor and $K_{\mathrm{op}}$ the value corresponding to crack opening stress. However, it seems that some studies supported the concept of crack closure (Budiansky and Hutchinson, 1978), and some others questioned the crack closure consideration. The paper by Vasudevan et al. (1994) indicated that crack closure could exist, but its magnitude was either small or negligible. For this, Walker (1970) proposed an empirical

\footnotetext{
* Corresponding author. Tel.: +8610 82543966; fax: +8610 62561284 . E-mail address: hongys@imech.ac.cn (Y. Hong).
}

fatigue crack growth model accounting for the effect of stress ratio $R$, with $\mathrm{d} a / \mathrm{d} N=C\left[(1-R)^{p} \Delta K\right]^{m}(C, p$ and $m$ are material parameters). This model is frequently used to account for the effect of $R$. Further, Sadananda and Vasudevan (2003) showed that an ordinary description of fatigue crack growth required two loading parameters $\Delta K$ and $\Delta K_{\max }$ without invoking any extraneous factors such as crack closure. In their model, the parameters of two critical thresholds $\Delta K_{\mathrm{th}}^{*}$ and $\Delta K_{\max }^{*}$ were adopted. For a fatigue crack to grow, both $\Delta K$ and $\Delta K_{\max }$ must exceed their respective threshold values. Moreover, Elber (1971) introduced the threshold value of crack propagation $\Delta K_{\text {th }}$ into the expression of crack growth rate with the form of $\mathrm{da} /$ $\mathrm{d} N=C\left(\Delta K-\Delta K_{\mathrm{th}}\right)^{m}$, which considered the behavior of crack growth rate in the near-threshold region. Later, Kujawski (2001a) proposed a fatigue crack driving force parameter $K^{*}=\left(K_{\max }\right)^{\alpha}\left(\Delta K^{+}\right)^{1-\alpha}$ for correlating long and short crack growth rate incorporating the effect of $R$, in which $\Delta K^{+}$denoted the positive part of $\Delta K$, and $\alpha$ was a parameter depending on the related material, temperature and environment. The comparison of experimental data for ten different types of materials indicated that the parameter $K^{*}$ was equally effective or better than $\Delta K_{\text {eff }}$ in correlating and predicting the effect of $R$ on crack growth rate 
(Dinda and Kujawski, 2004). In addition, Noroozi et al. (2005) proposed a two parameter driving force model based on the analysis of elastic-plastic stress-strain history at crack tip, which showed that the crack growth rate was controlled by a two parameter driving force $K_{\text {max tot }}^{p} \Delta K_{\text {tot }}^{1-p}$, where the resultant maximum stress intensity factor $K_{\text {max,tot }}$ and the resultant stress intensity range $\Delta K_{\text {tot }}$ contained the effect of residual stress.

Although the modeling of crack growth rate has been widely studied, the proposed models mainly focus on the crack growth rate above the threshold value of crack propagation $\Delta K_{\text {th }}$ with respect to the crack growth rate in an intermediate region $\left(10^{-9}\right.$ to $10^{-6} \mathrm{~m} /$ cycle $)$ described by Paris relation. There seems not any model reported for the effect of stress ratio on fatigue crack growth rate below $10^{-10} \mathrm{~m} /$ cycle. The value of $\Delta K$ corresponding to the crack growth rate at $10^{-10} \mathrm{~m} /$ cycle is commonly defined as the value of $\Delta K_{\mathrm{th}}$, and the crack growth rate is thought to be zero for $\Delta K$ lower than $\Delta K_{\mathrm{th}}$. As a matter of fact, the crack initiation and early growth exist at the stage that the value of $\Delta K$ less than $\Delta K_{\mathrm{th}}$, i.e. the crack growth rate is not zero. The investigation for very-high-cycle fatigue (VHCF) has shown that the crack growth rate in crack initiation and early growth stage is much less than $10^{-10} \mathrm{~m} /$ cycle (Murakami et al., 1999; Tanaka and Akiniwa, 2002; Sun et al., 2012; Hong et al., 2014). The investigation on fatigue crack behavior in VHCF regime by Pippan et al. (2002) also showed that there existed a lower limit for the crack driving force at which cracks did not propagate ( $\mathrm{d} a / \mathrm{d} N$ smaller than $10^{-13} \mathrm{~m} /$ cycle) for constant and variable amplitude loadings. These results suggest that fatigue crack growth still occurs at a very low rate. Therefore, it is of importance to investigate the fatigue crack growth rate during the stage close to and below the value of $\Delta K_{\text {th }}$ with the effect of stress ratio. It is noted that, in the early stage of fatigue process for VHCF, the crack growth length per cycle mentioned above is far below Burgers vector. This is understandable that the fatigue crack growth is not produced cycle by cycle, and for a two dimensional crack, its growth is sporadically along the circumference in the early stage of fatigue process. Thus, it seems reasonable to call it "equivalent crack growth rate" or "mean crack growth rate". In the present paper, we just call it crack growth rate for convenience.

It is also noted that, a number of investigations have shown that the failure of high strength steels in VHCF is mostly caused by interior non-metallic inclusions and a kind of fish-eye fracture mode is often presented as fracture origin (Murakami et al., 1999; Sakai et al., 2002; Dominguez Almaraz, 2008; Hong et al., 2012). For interior initiated failure mode, one can hardly measure the evolvement process of the internal crack. For this, Stanzl-Tschegg and SchÖnbauer (2010) studied the near-threshold fatigue crack propagation of specimens for a chromium steel at very high number of loading cycles. They showed that the VHCF fracture surfaces of specimens tested in vacuum presented similar features as the specimens in which fisheye fractures prevailed. This suggested that the result from the crack growth rate close to and below the value of $\Delta K_{\text {th }}$ may be also applicable for VHCF regime.

Based on above considerations, the effect of stress ratio $R$ on fatigue crack growth rate for the region that close to and below the value of $\Delta K_{\text {th }}$ is investigated in this paper. A fatigue crack growth rate model with the effect of $R$ is developed, which is independent of whether crack closure exists or not. Then, a formula is derived for the effect of $R$ (or mean stress) on fatigue strength, and the model predictions are compared with experimental data for high cycle fatigue and VHCF in literature. The comparison of the simulations by the present formula with that by Goodman formula is also discussed.

\section{Effect of stress ratio on crack growth rate}

As known, Paris relation has achieved great success in correlating the parameters of fatigue crack growth rate, cyclic stress and crack length. This relation is also successfully extended to describe the effect of stress ratio $R$ on fatigue crack growth rate even for the stage close to the lower end of Paris region in some cases. In this paper, it is assumed that the fatigue crack growth rate below the value of $\Delta K_{\text {th }}$ is also expressed by a function of $\Delta K$. Now, let us see the effect of $R$ on the fatigue crack growth rate $\mathrm{d} a /$ $\mathrm{d} N$. First, the effect of $R$ on $\mathrm{d} a / \mathrm{d} N$ close to or less than $\Delta K_{\mathrm{th}}$ is written as a function of $f(R) \Delta K$, such that:

$\frac{\mathrm{d} a}{\mathrm{~d} N}=F(f(R) \Delta K)$

where $f(R)$ is a function of $R, F$ is a function of $f(R) \Delta K$, and $f(R) \Delta K$ is an effective stress intensity factor range $\Delta K_{\mathrm{e}}$, i.e. $f(R) \Delta K=\Delta K_{\mathrm{e}}$.

If the effect of $R$ on crack growth rate is presented by Eq. (1), one obtains the same value of $\mathrm{d} a / \mathrm{d} N$ for the identical value of $f(R) \Delta K$. In other words, if the value of $\mathrm{d} a / \mathrm{d} N$ is given by the identical value of $f(R) \Delta K$, Eq. (1) reflects the effect of $R$ on crack growth rate. This provides a clue for determining the function $f(R)$ through the same crack growth rate and the associated stress intensity factor range at different stress ratios. Fig. 1 plots several groups of data of $\Delta K$ versus $R$ for a certain crack growth rate close to or lower than $10^{-10} \mathrm{~m} /$ cycle for steels and aluminum alloys. It is seen that, for the materials in Fig. 1(a) and (c), the function $f(R)$ is expressed as $f(R)=(1-R)^{-\alpha}=A / \Delta K$, i.e. $\Delta K(1-R)^{-\alpha}=\Delta K_{0}$, where $A$ and $\alpha$ are material constants, and $\Delta K_{0}$ denotes the stress intensity factor range at $R=0$. While for the cases in Fig. 1(b) and (d), $f(R)$ is better expressed as a piecewise function: $f(R)=(1-R)^{-\alpha}=A / \Delta K$ for $R \geqslant 0$ and $f(R)=(1-R)^{-1}=A / \Delta K$ for $R<0$, or in general, $\Delta K_{0}=K^{*}=\left(K_{\max }\right)^{\alpha}\left(\Delta K^{+}\right)^{1-\alpha}$ (Kujawski, 2001a; Dinda and Kujawski, 2004). This result indicates that for the crack growth rate at the stress intensity factor range close to and lower than $\Delta K_{\text {th }}$ the function $f(R)$ may be written as the following form

$f(R)= \begin{cases}(1-R)^{-\gamma} & (R<0) \\ (1-R)^{-\alpha} & (R \geqslant 0)\end{cases}$

For verifying this result, Figs. 2-7 show the crack growth rate data taken from literature as a function of $\Delta K$ or $\Delta K_{\mathrm{e}}=f(R) \Delta K$ for the effect of $R$. It is seen that the proposed model Eq. (2) is capable of describing the effect of $R$ on the crack growth rate close to and below the value of $\Delta K_{\mathrm{th}}$. This model also appropriately reflects the effect of 


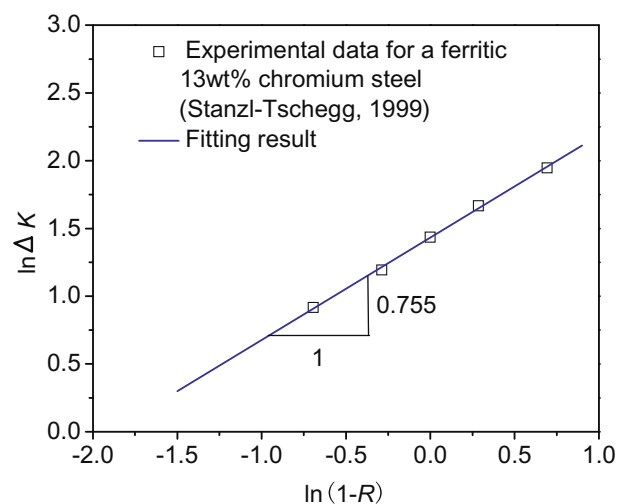

(a)

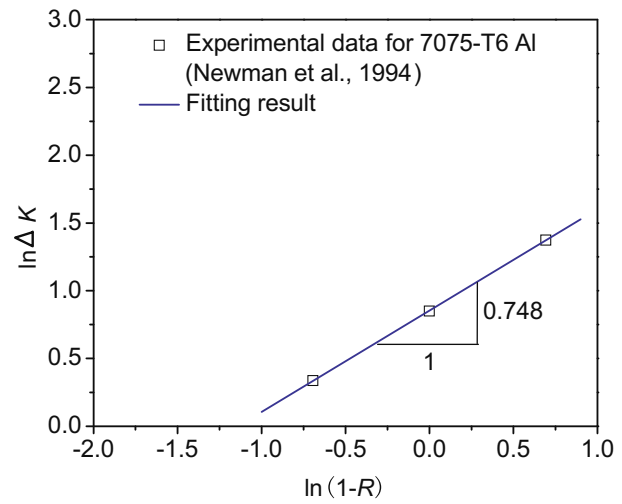

(c)

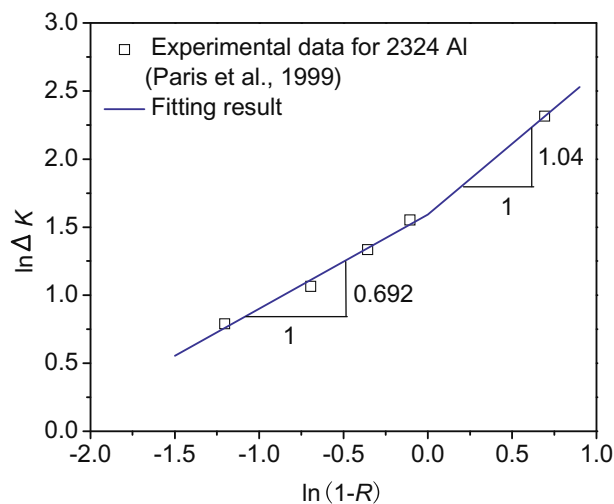

(b)

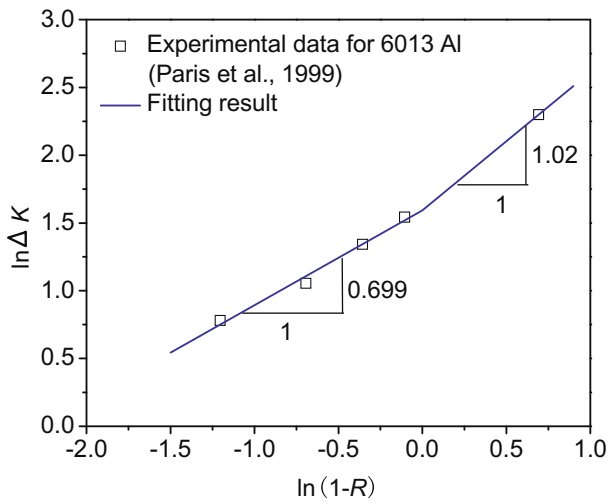

(d)

Fig. 1. Relation between $\ln \Delta K$ and $\ln (1-R)$. (a) $\mathrm{d} a / \mathrm{d} N=3.75 \times 10^{-13} \mathrm{~m} /$ cycle; (b) $\mathrm{d} a / \mathrm{d} N=1.2 \times 10^{-10} \mathrm{~m} / \mathrm{cycle} ;(\mathrm{c}) \mathrm{d} a / \mathrm{d} N=1 \times 10^{-11} \mathrm{~m} / \mathrm{cycle}$; and (d) da/ $\mathrm{d} N=2 \times 10^{-10} \mathrm{~m} /$ cycle.

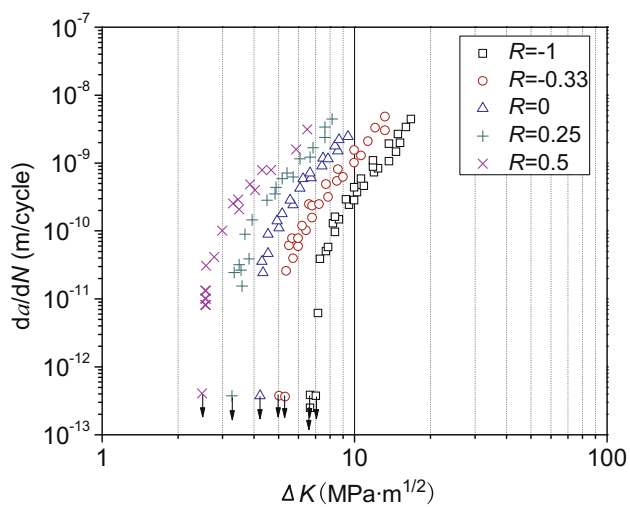

(a)

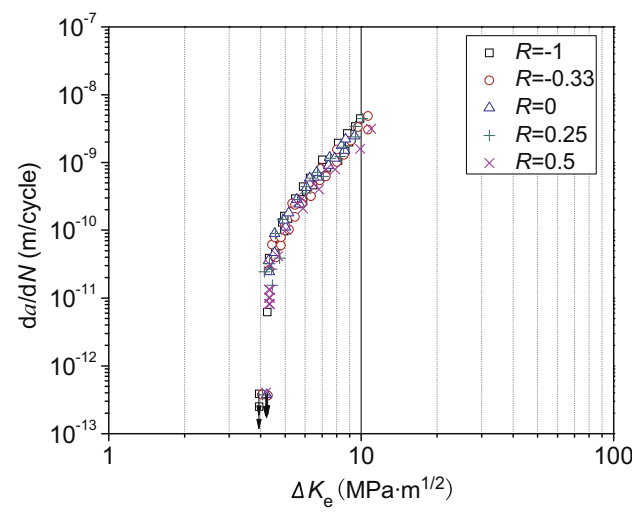

(b)

Fig. 2. Crack growth rate of a ferritic $13 \mathrm{wt} \%$ chromium steel (Stanzl-Tschegg, 1999). (a) $\Delta K$ vs da/d $N$; and (b) $\Delta K_{\mathrm{e}} \mathrm{vs} \mathrm{d} a / \mathrm{d} N$, with $\Delta K_{\mathrm{e}}=(1-R)^{-0.755} \Delta K$.

$R$ on crack growth rate in Paris region and even in crack fast growth region. In other words, the effect of $R$ on the crack growth rate in Paris region and in the near-threshold region (crack growth rate lower than $10^{-10} \mathrm{~m} /$ cycle) can be described by a unified form of Eq. (2).

In general, this investigation indicates that the effect of $R$ on crack growth rate for the region involving that close to and lower than $\Delta K_{\text {th }}$ is described by a piecewise function for some materials (e.g. Figs. 3, 5 and 6), i.e. $\Delta K_{\mathrm{e}}=\left(K_{\max }\right)^{\alpha}\left(\Delta K^{+}\right)^{1-\alpha}$ as that proposed by Kujawski (2001a) for correlating long and short crack growth rate with the effect of $R$. But the concept proposed in the present paper differs from that by the previous paper. Here, the crack growth behavior close to and lower than $\Delta K_{\text {th }}$ is taken into account, and the crack growth rate close to or lower than $\Delta K_{\mathrm{th}}$ is used for the determination of parameter 


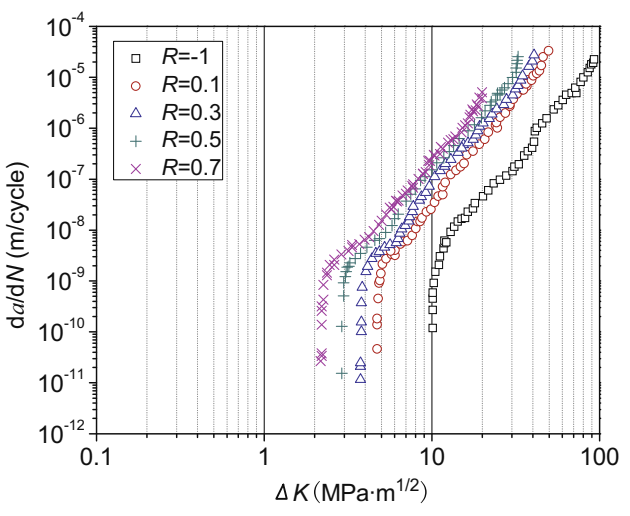

(a)

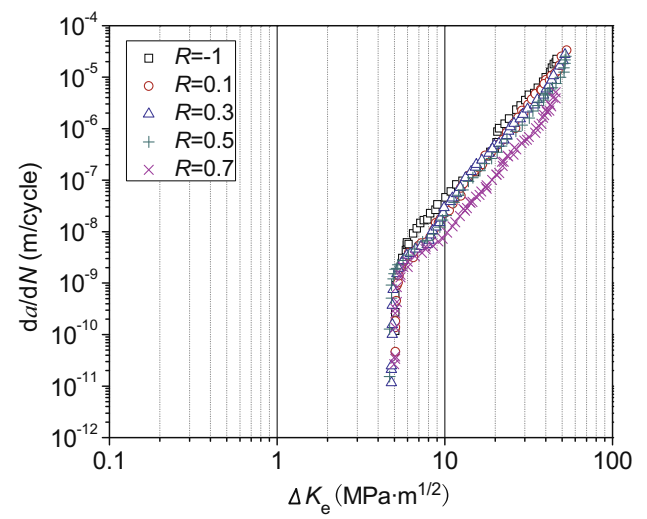

(b)

Fig. 3. Crack growth rate of $2324 \mathrm{Al}$ (Paris et al., 1999). (a) $\Delta K$ vs da/dN; and (b) $\Delta K_{\mathrm{e}} \mathrm{vs} \mathrm{d} a / \mathrm{d} N$, with $\Delta K_{\mathrm{e}}=\left(K_{\mathrm{max}}\right)^{0.692}\left(\Delta K^{+}\right)^{0.308}$.

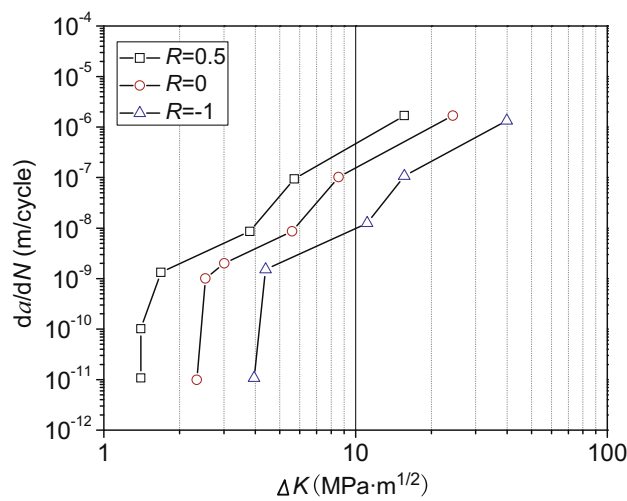

(a)

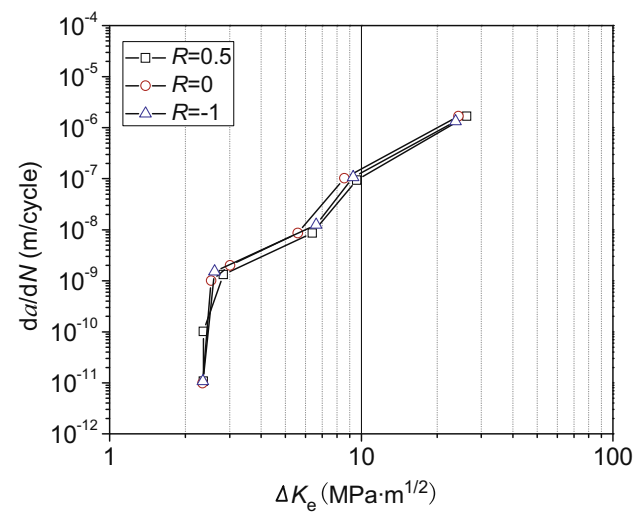

(b)

Fig. 4. Crack growth rate of 7075-T6 Al (Newman et al., 1994). (a) $\Delta K$ vs da/d $N$; and (b) $\Delta K_{\mathrm{e}}$ vs da/dN, with $\Delta K_{\mathrm{e}}=(1-R)^{-0.748} \Delta K$.

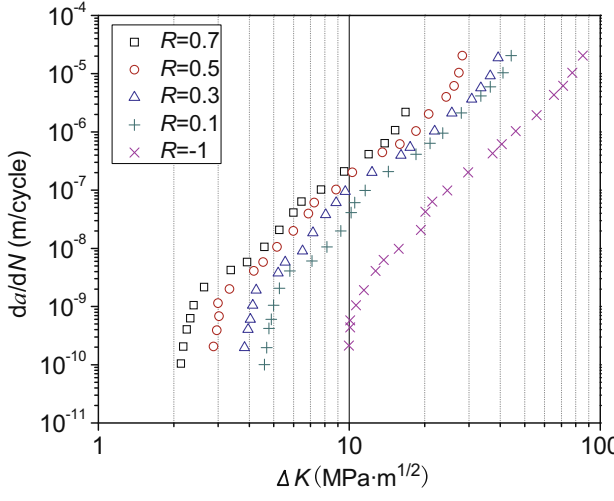

(a)

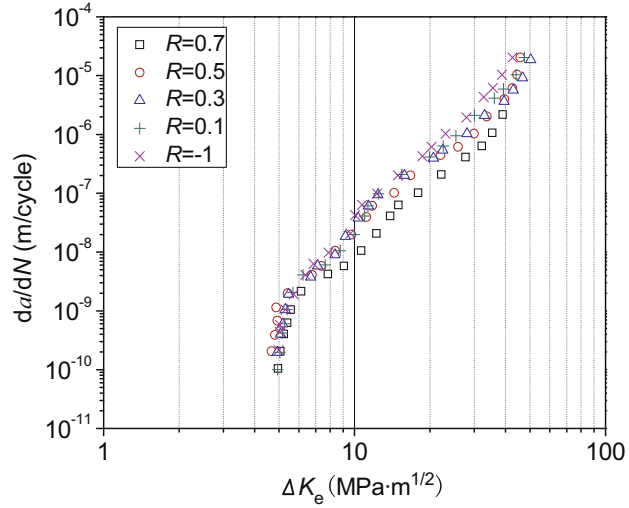

(b)

Fig. 5. Crack growth rate of $6013 \mathrm{Al}$ (Paris et al., 1999). (a) $\Delta K \mathrm{vs} \mathrm{d} a / \mathrm{d} N$; and (b) $\Delta K_{\mathrm{e}} \mathrm{vs} \mathrm{d} a / \mathrm{d} N$, with $\Delta K_{\mathrm{e}}=\left(K_{\mathrm{max}}\right)^{0.699}\left(\Delta K^{+}\right)^{0.301}$.

$\alpha$. For comparison, Figs. 8 and 9 represent the crack growth rate data versus $\left(K_{\max } \Delta K^{+}\right)^{0.5}$ by Kujawski (2001b) for the effect of $R$. It is seen that the driving force parameter $\left(K_{\max } \Delta K^{+}\right)^{0.5}$ correlates well the effect of $R$ for crack growth rate in Paris region. Whereas it does not correlate well the effect of $R$ for the crack growth rate close to and lower than $\Delta K_{\mathrm{th}}$. It is common that the smaller the crack growth rate is, the longer the fatigue life will be. For example, when 


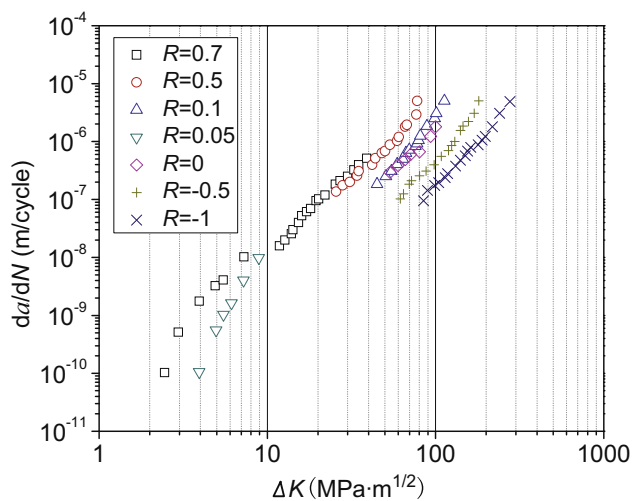

(a)

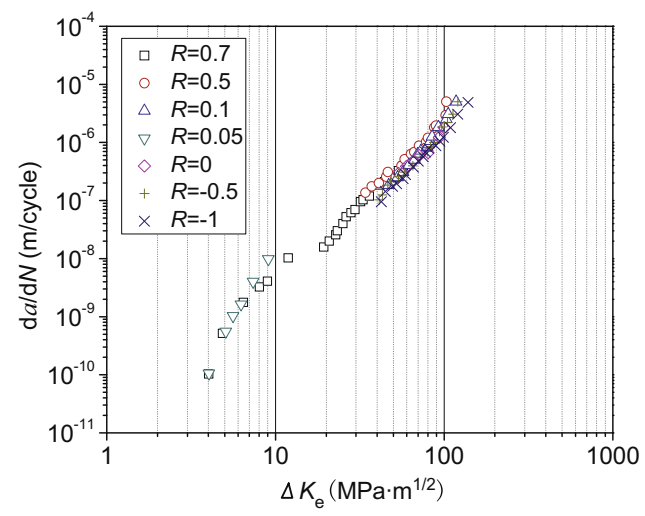

(b)

Fig. 6. Crack growth rate of 4340 steel (Noroozi et al., 2005). (a) $\Delta K$ vs da/dN; and (b) $\Delta K_{\mathrm{e}} \mathrm{vs} \mathrm{d} a / \mathrm{d} N$, with $\Delta K_{\mathrm{e}}=\left(K_{\mathrm{max}}\right)^{0.41}\left(\Delta K^{+}\right)^{0.59}$.

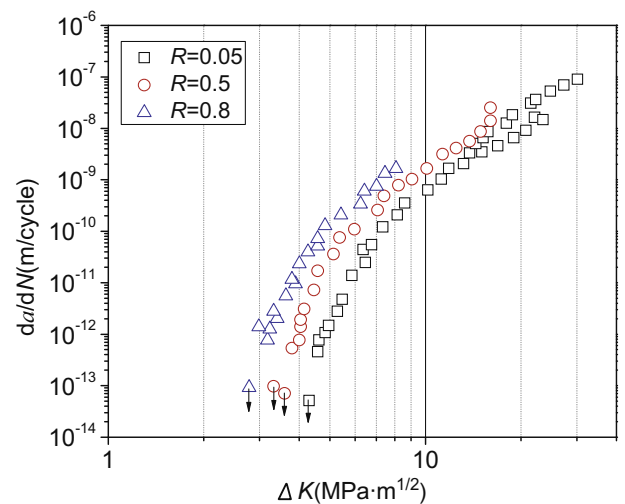

(a)

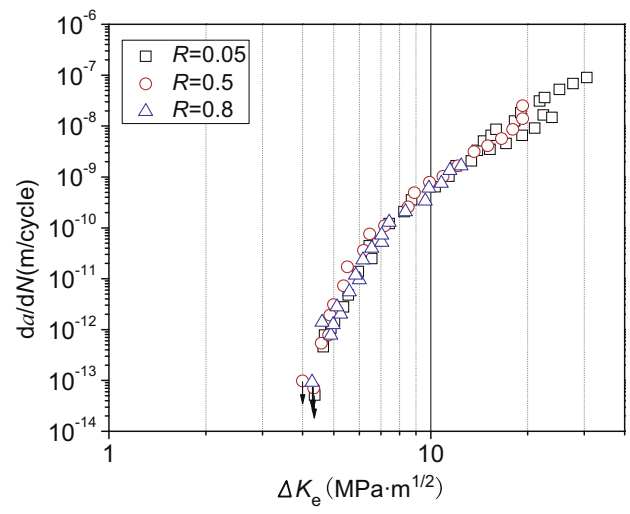

(b)

Fig. 7. Crack growth rate for a chromium steel in vacuum (Stanzl-Tschegg and SchÖnbauer, 2010). (a) $\Delta K$ vs da/d $N$; and (b) $\Delta K$ e vs da/d $N$, with $\Delta K_{\mathrm{e}}=(1-R)^{-0.268} \Delta K$.

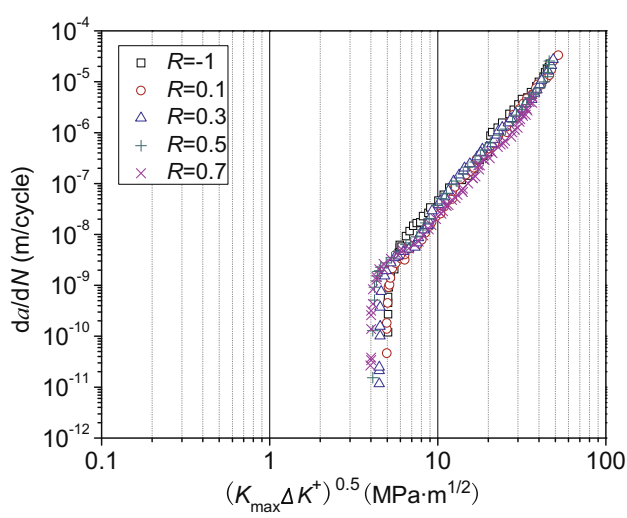

Fig. 8. Crack growth rate of $2324 \mathrm{Al}$ (Paris et al., 1999) versus $\left(K_{\max } \Delta K^{+}\right)^{0.5}$ by Kujawski (2001b).

the value of $\Delta K_{\mathrm{e}}$ ranges from $5 \mathrm{MPa} \mathrm{m}^{1 / 2}$ to $7 \mathrm{MPa} \mathrm{m}^{1 / 2}$, the fatigue life is approximately $79 \%$ of the total fatigue life for the material shown in Fig. 3 and $77 \%$ of the total fatigue life for the material shown in Fig. 5. Therefore, it is more

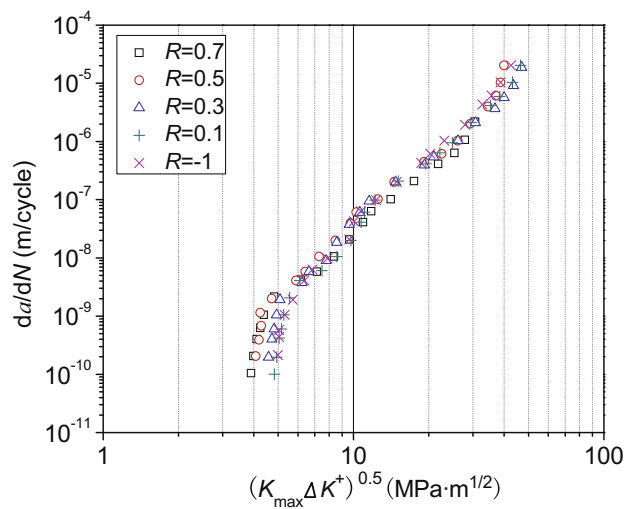

Fig. 9. Crack growth rate of $6013 \mathrm{Al}$ (Paris et al., 1999) versus $\left(K_{\max } \Delta K^{+}\right)^{0.5}$ by Kujawski (2001b).

appropriate to use the crack growth rate close to and lower than $\Delta K_{\text {th }}$ for determining the parameter $\alpha$, especially when the near-threshold crack growth rate dominates or the longer fatigue life prevails. 


\section{Crack growth rate model}

The downward trend of $\mathrm{d} a / \mathrm{d} N$ is becoming dramatic with the decrease of $\Delta K$ especially when $\Delta K$ is lower than $\Delta K_{\text {th }}$. So, the expression of crack growth rate (with the effect of $R$ ) for the region involving that close to and lower than $\Delta K_{\mathrm{th}}$ may have the similar form as that proposed by Elber (1971), that is

$\frac{\mathrm{d} a}{\mathrm{~d} N}=C\left(f(R) \Delta K-\Delta K_{\mathrm{th}, 0}^{\prime}\right)^{m}=C\left(\Delta K_{0}-\Delta K_{\mathrm{th}, 0}^{\prime}\right)^{m}$

where $\Delta K_{\mathrm{th}, 0}^{\prime}$ denotes the threshold value of crack initiation at $R=0$.

Fig. 10 plots the crack growth rate versus $\Delta K_{\mathrm{e}}=f(R) \Delta K$ with the fitting curve. It is seen that Eq. (3) well describes the crack growth rate even when the value of $\Delta K$ is much lower than the value of $\Delta K_{\mathrm{th}}$, namely that the crack growth rate (with the effect of $R$ ) for the region involving that close to and lower than $\Delta K_{\mathrm{th}}$ can be expressed by the form of Eq. (3). The lowest crack growth rate in Fig. 10(f) is about $4.5 \times 10^{-13} \mathrm{~m} /$ cycle, which means that the crack growth length per cycle is much lower than the magnitude of Burgers vector. For this, the explanations are: (1) in general, crack growth length is not produced cycle by cycle in the early stage of fatigue process, and (2) by considering a planar crack, its growth is discontinuous and sporadic with regard to the circumference of $360^{\circ}$.

Fig. 11 gives the crack growth rate in VHCF regime from our recent paper (Lei et al., 2012) with the fitting result by Eq. (3). It is observed that Eq. (3) describes the trend of the crack growth rate with the value of $\Delta K$ with respect to VHCF.

\section{Effect of stress ratio on fatigue strength}

The above analysis indicates that the crack growth rate for different values of $R$ can be expressed as a unified form of:

$\frac{\mathrm{d} a}{\mathrm{~d} N}=F(f(R) \Delta K)=F\left(\Delta K_{0}\right)$

Based on Eq. (4), for a crack growing from length $a_{0}$ to length $a_{1}$ at two stress ratios of $R_{1}$ and $R_{2}$, we have

$\int_{a_{0}}^{a_{1}} \frac{\mathrm{d} a}{F\left(f\left(R_{1}\right) \Delta K_{R_{1}}\right)}=\int_{a_{0}}^{a_{1}} \frac{\mathrm{d} a}{F\left(f\left(R_{2}\right) \Delta K_{R_{2}}\right)}$

Note that

$f\left(R_{1}\right) \Delta \sigma_{R_{1}}=f\left(R_{2}\right) \Delta \sigma_{R_{2}}$

Eq. (6) is derived as follows.

Eq. (5) can be rewritten as

$\int_{a_{0}}^{a_{1}} \frac{F\left(f\left(R_{2}\right) \Delta K_{R_{2}}\right)-F\left(f\left(R_{1}\right) \Delta K_{R_{1}}\right)}{F\left(f\left(R_{1}\right) \Delta K_{R_{1}}\right) F\left(f\left(R_{2}\right) \Delta K_{R_{2}}\right)} \mathrm{d} a=0$

Suppose that $f\left(R_{1}\right) \Delta \sigma_{R_{1}} \neq f\left(R_{2}\right) \Delta \sigma_{R_{2}}$, that is, $f\left(R_{1}\right) \Delta \sigma_{R_{1}}>f\left(R_{2}\right) \Delta \sigma_{R_{2}}$ or $f\left(R_{1}\right) \Delta \sigma_{R_{1}}<f\left(R_{2}\right) \Delta \sigma_{R_{2}}$, then we have $f\left(R_{1}\right) \Delta K_{R_{1}}>f\left(R_{2}\right) \Delta K_{R_{2}}$ or $f\left(R_{1}\right) \Delta K_{R_{1}}<f\left(R_{2}\right) \Delta K_{R_{2}}$ for arbitrary $a \in\left(a_{0}, a_{1}\right)$. Due to the fact that the crack growth rate usually increases monotonously with the increasing of stress intensity factor range $f(R) \Delta K=\Delta K_{0}$, we have $F\left(f\left(R_{2}\right) \Delta K_{R_{2}}\right)-F\left(f\left(R_{1}\right) \Delta K_{R_{1}}\right)<0$ or $F\left(f\left(R_{2}\right) \Delta K_{R_{2}}\right)-F\left(f\left(R_{1}\right) \Delta K_{R_{1}}\right)>0$. Thus,

$\int_{a_{0}}^{a_{1}} \frac{F\left(f\left(R_{2}\right) \Delta K_{R_{2}}\right)-F\left(f\left(R_{1}\right) \Delta K_{R_{1}}\right)}{F\left(f\left(R_{1}\right) \Delta K_{R_{1}}\right) F\left(f\left(R_{2}\right) \Delta K_{R_{2}}\right)} \mathrm{d} a<0$

or

$\int_{a_{0}}^{a_{1}} \frac{F\left(f\left(R_{2}\right) \Delta K_{R_{2}}\right)-F\left(f\left(R_{1}\right) \Delta K_{R_{1}}\right)}{F\left(f\left(R_{1}\right) \Delta K_{R_{1}}\right) F\left(f\left(R_{2}\right) \Delta K_{R_{2}}\right)} \mathrm{d} a>0$

Eqs. (8) and (9) conflict with Eq. (7). Therefore, Eq. (6) is proved.

Further, by using Eq. (2) and for the stress amplitude at two stress ratios of $R_{1}$ and $R_{2}$, we have

$$
\begin{aligned}
& \sigma_{a, R_{2}}=\left(\frac{1-R_{2}}{1-R_{1}}\right)^{\gamma} \sigma_{a, R_{1}} \text { for } R_{1}<R_{2}<0 \\
& \sigma_{a, R_{2}}=\left(\frac{1-R_{2}}{1-R_{1}}\right)^{\alpha} \sigma_{a, R_{1}} \text { for } R_{1}>R_{2} \geqslant 0 \\
& \sigma_{a, R_{2}}=\frac{\left(1-R_{2}\right)^{\alpha}}{\left(1-R_{1}\right)^{\gamma}} \sigma_{a, R_{1}} \text { for } R_{1}<0 \text { and } R_{2} \geqslant 0
\end{aligned}
$$

Especially, if $\alpha=\gamma$, we have

$\sigma_{a, R_{2}}=\left(\frac{1-R_{2}}{1-R_{1}}\right)^{\alpha} \sigma_{a, R_{1}}$

Eqs. (10) to (13) imply that, for the same material with the same fatigue life, the fatigue strength at any stress ratio $R_{2}$ can be obtained by the fatigue strength at a certain stress ratio $R_{1}$.

Table 1 shows the value of parameter $\alpha$ obtained by Eq. (13) for five groups of experimental data with the same median logarithmic life by Li et al. (2007) for a medium carbon steel. It is seen that the value of $\alpha$ approximates to 0 except for the first group of experimental data. This result is in agreement with Eq. (13), indicating that $\alpha$ is independent of fatigue life and $R$. Kondo et al. (2003) plotted the stress ratio $\sigma_{a} / \sigma_{-1}$ versus $(1-R) / 2$ on the fatigue limit ( $10^{7}$ cycles) of short pre-cracked specimen for three steels SCM435, S45C and S25C in logarithm scale, and also showed that the effect of $R$ on fatigue strength was well correlated by a linear form of $(1-R) / 2$ in logarithm scale with the slopes of 0.8 for SCM435, 0.6 for S45C and 0.3 for S25C. These results further indicate that the present model of Eq. (13) correlates the fatigue strength with different values of $R$.

Here, we consider the form $f(R)=(1-R)^{-\alpha}$ for a large range of stress ratios. In other words, we consider using Eq. (13) for describing the effect of $R$ on fatigue strength for a whole region including low cycle, high cycle and VHCF regimes. Fig. 12 shows the comparison of the estimated results of fatigue strength by present model of Eq. (13) with experimental data for an extruded magnesium alloy AZ31 by Ishihara et al. (2009) in low cycle and high cycle fatigue regime, where $\alpha$ is determined by the fatigue strength at fatigue life near $7 \times 10^{5}$ cycles for $R=0.1$ and $R=-2$. Fig. 13 shows the comparisons for a bearing steel by Shiozawa et al. (2009) from low cycle to VHCF regime. For this case, $\alpha$ is calculated by the fatigue 


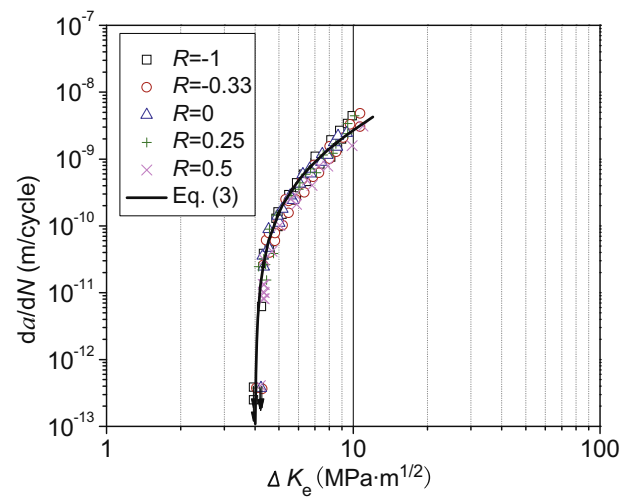

(a)

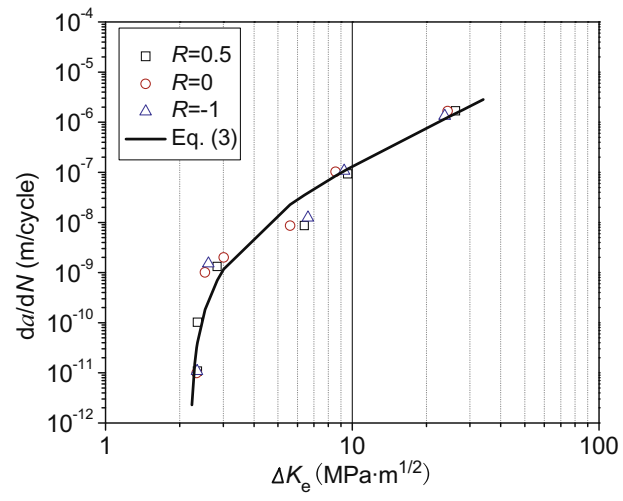

(c)

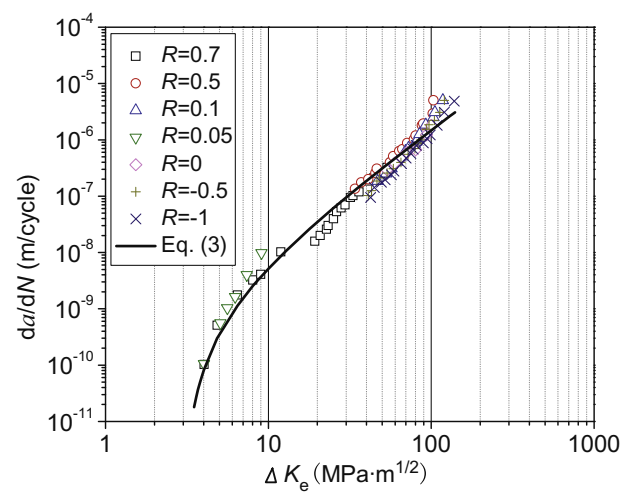

(e)

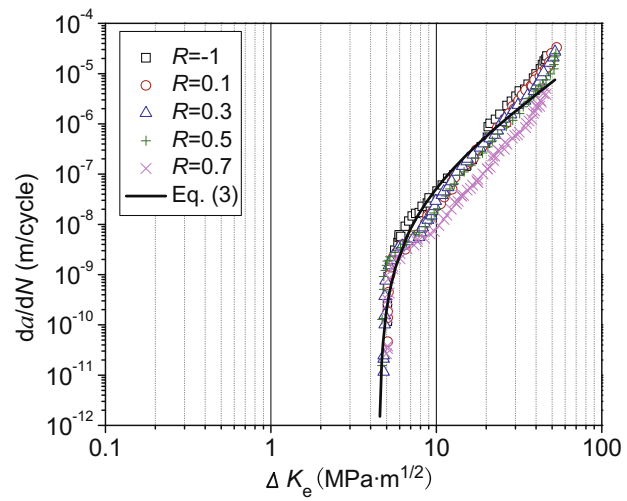

(b)

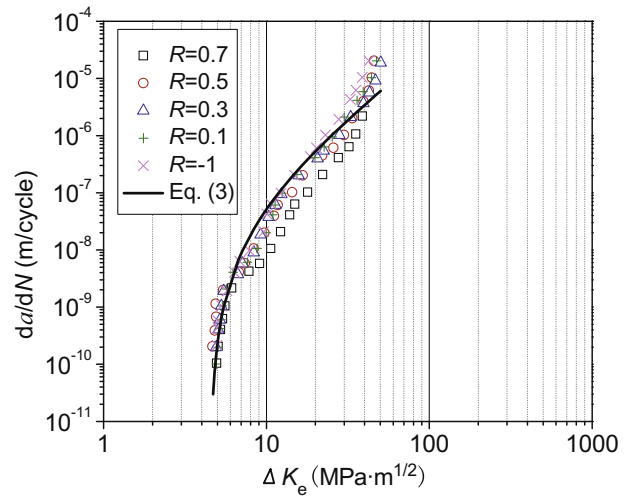

(d)

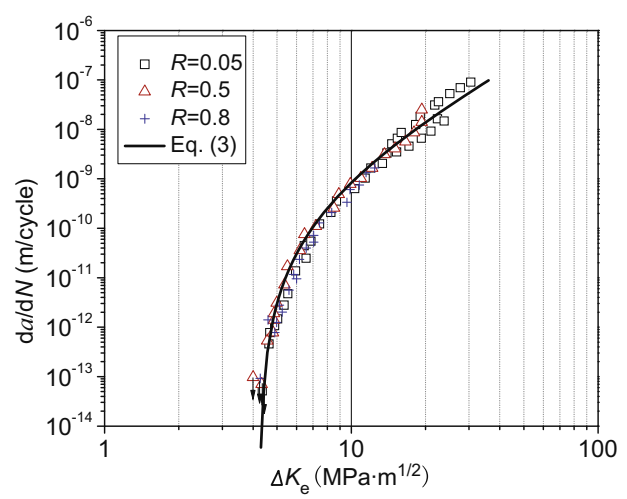

(f)

Fig. 10. Crack growth rate versus $\Delta K_{\mathrm{e}}=f(R) \Delta K$ with fitting result by Eq. (3). (a)-(f) corresponds to Figs. 2(b), 3(b), 4(b), 5(b), 6(b), 7(b), respectively.

strength at fatigue life near $4 \times 10^{6}$ cycles for $R=-1$ and $R=0$, which has almost the same inclusion size at fracture origin. It is seen that the trend of estimated fatigue strength by the present model versus the fatigue life is in good agreement with that of the experimental data excepted for a couple of datum points. It is evident that, the present model of Eq. (13) is capable of correlating the effect of $R$ on fatigue strength not only for the case of low cycle and high cycle fatigue regimes but also for that of VHCF regime. The experimental data by Takeuchi et al. (2010) for Ti-6Al-4V at $10^{8}$ and $10^{10}$ cycles also indicated that the effect of $R$ on fatigue strength was well correlated by a linear form of $(1-R) / 2$ in logarithm scale. It is noted that, for VHCF of high strength steels, the failure is mostly originated by interior non-metallic inclusions. The inclusion size, geometrical property and its bonding condition with the matrix will influence the fatigue behavior (Murakami et al., 1999; Sakai et al., 2002; Dominguez Almaraz, 2008; Shiozawa et al, 2009; Hong et al., 2012). In Fig. 13, the difference of defect 


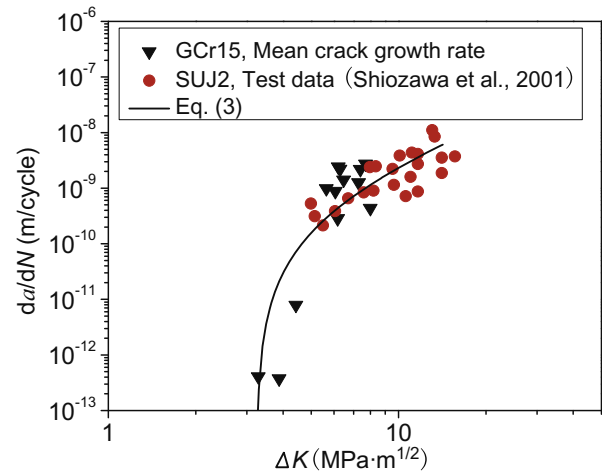

Fig. 11. Crack growth rate containing VHCF (Lei et al., 2012) with the fitting result by Eq. (3).

(e.g. inclusion size) is not considered, which may have the effect on the estimated results.

\section{Comparison with Goodman formula}

For further illustrating the present model on the effect of stress ratio $R$ (or mean stress), the result of Eq. (13) is compared with that from the well-known Goodman formula. Without losing generality, we take $R_{1}=-1$ in Eq. (13) and obtain

$\sigma_{a, R}=\sigma_{-1}\left(\frac{1-R}{2}\right)^{\alpha}=\sigma_{-1}\left(1-\frac{\sigma_{\mathrm{avg}, R}}{\sigma_{\mathrm{max}, R}}\right)^{\alpha}$

where $\sigma_{a, R}$ is the stress amplitude with respect to $R$, and $\sigma_{-1}$ is the stress amplitude at $R=-1$.

Goodman formula is written as the following form

$\sigma_{a, R}=\sigma_{-1}\left[1+\frac{\sigma_{-1}(1+R)}{\sigma_{\mathrm{b}}(1-R)}\right]^{-1}$

where $\sigma_{\mathrm{b}}$ is the tensile strength.

Fig. 14 plots the comparison of the result by Eq. (14) with that by Goodman formula. It is seen that the effect of $R$ on fatigue strength by Goodman formula is related to the ratio $\sigma_{-1} / \sigma_{\mathrm{b}}$. With the increase of $\sigma_{-1} / \sigma_{\mathrm{b}}$, the fatigue strength by Goodman formula relative to that at $R=-1$ is decreased, that is to say, the relative fatigue strength

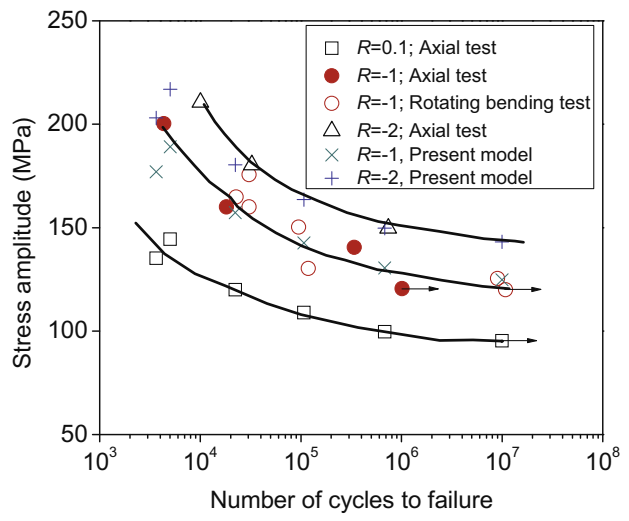

Fig. 12. Comparison of estimated fatigue strength by Eq. (13) with experimental data for an extruded magnesium alloy AZ31 by Ishihara et al. (2009) for low cycle and high cycle fatigue.

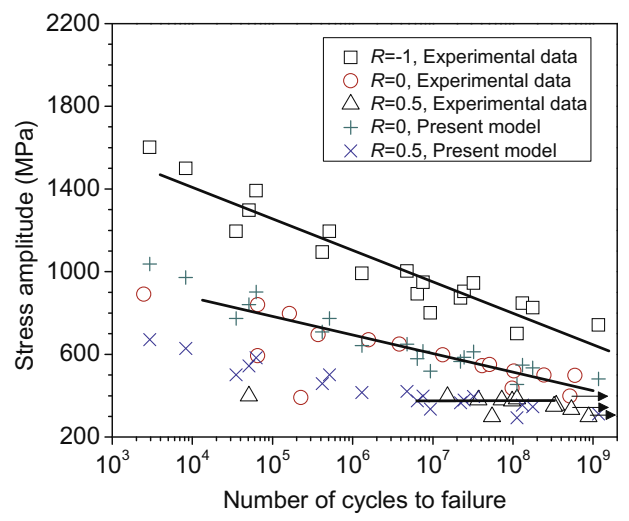

Fig. 13. Comparison of estimated fatigue strength by Eq. (13) with experimental data for a bearing steel by Shiozawa et al. (2009) from low cycle to VHCF.

$\sigma_{a, R} / \sigma_{-1}$ by Goodman formula decreases with decreasing the fatigue life. Whereas the effect of $R$ on the relative fatigue strength by the present model of Eq. (14) is only related to the parameter $\alpha$ determined by the related material, which is regardless of the fatigue life. Thus, the difference of the estimated results by the present model

Table 1

Value of parameter $\alpha$ by Eq. (13) for 5 groups of experimental data having the same median logarithmic life by Li et al. (2007) for a medium carbon steel.

\begin{tabular}{|c|c|c|c|c|c|c|c|}
\hline $\begin{array}{l}\text { Group } \\
\text { code }\end{array}$ & $\begin{array}{l}\text { Mean stress } \\
(\mathrm{MPa})\end{array}$ & $\begin{array}{l}\text { Maximum stress } \\
(\mathrm{MPa})\end{array}$ & $\begin{array}{l}\text { Number of } \\
\text { specimens }\end{array}$ & $\begin{array}{l}\text { Median logarithmic life } \\
\log _{10} N\end{array}$ & $\begin{array}{l}\text { Stress amplitude } \\
(\mathrm{MPa})\end{array}$ & $\begin{array}{l}\text { Stress } \\
\text { ratio } R\end{array}$ & $\begin{array}{l}\text { Value of } \\
\alpha\end{array}$ \\
\hline 1 & $\begin{array}{l}196 \\
294\end{array}$ & $\begin{array}{l}529.2 \\
646.8\end{array}$ & $\begin{array}{l}3 \\
3\end{array}$ & $\begin{array}{l}4.4935 \\
4.4935\end{array}$ & $\begin{array}{l}333.2 \\
352.8\end{array}$ & $\begin{array}{l}-0.259 \\
-0.091\end{array}$ & 0.398 \\
\hline 2 & $\begin{array}{l}196 \\
294\end{array}$ & $\begin{array}{l}509.6 \\
607.4\end{array}$ & $\begin{array}{l}3 \\
3\end{array}$ & $\begin{array}{l}4.7517 \\
4.7517\end{array}$ & $\begin{array}{l}313.6 \\
313.4\end{array}$ & $\begin{array}{l}-0.231 \\
-0.032\end{array}$ & -0.00362 \\
\hline 3 & $\begin{array}{l}294 \\
196\end{array}$ & $\begin{array}{l}588 \\
490\end{array}$ & $\begin{array}{l}3 \\
3\end{array}$ & $\begin{array}{l}4.9871 \\
4.9872\end{array}$ & $\begin{array}{l}294 \\
294\end{array}$ & $\begin{array}{l}0 \\
-0.200\end{array}$ & 0 \\
\hline 4 & $\begin{array}{l}196 \\
294\end{array}$ & $\begin{array}{l}470.4 \\
568.4\end{array}$ & $\begin{array}{l}3 \\
3\end{array}$ & $\begin{array}{l}5.2238 \\
5.2238\end{array}$ & $\begin{array}{l}274.4 \\
274.4\end{array}$ & $\begin{array}{r}-0.167 \\
0.034\end{array}$ & 0 \\
\hline 5 & $\begin{array}{l}196 \\
294\end{array}$ & $\begin{array}{l}450.8 \\
548.8\end{array}$ & $\begin{array}{l}3 \\
4\end{array}$ & $\begin{array}{l}5.5693 \\
5.5693\end{array}$ & $\begin{array}{l}254.8 \\
254.8\end{array}$ & $\begin{array}{r}-0.130 \\
0.071\end{array}$ & 0 \\
\hline
\end{tabular}


and those by Goodman formula is not only related to the stress ratio but also related to the material and the fatigue life investigated. The difference of the estimated results may be either very large or very small, which depends on the related material, stress ratio and the value of fatigue life.

As described in the present model, the effect of $R$ is expressed as a piecewise function for some materials, with $f(R)=(1-R)^{-\alpha}$ for $R \geqslant 0$, and $f(R)=(1-R)^{-1}$ for $R<0$. Taking $R_{1}=-1$ for Eq. (12), we have

$$
\sigma_{a, R}=\left\{\begin{array}{l}
\sigma_{-1} \frac{(1-R)^{\alpha}}{2}=2^{\alpha-1} \sigma_{-1}\left(1-\frac{\sigma_{\mathrm{avg}, R}}{\sigma_{\max , R}}\right)^{\alpha} \text { for } R \geqslant 0 \\
\sigma_{-1} \frac{1-R}{2}=\sigma_{-1}\left(1-\frac{\sigma_{\mathrm{avg}, R}}{\sigma_{\max , R}}\right) \text { for } R<0
\end{array}\right.
$$

The result by Eq. (16) is also compared with that by Goodman formula, which is shown in Fig. 15. It is observed that, similar to the previous comparisons shown in Fig. 14, the difference between Eq. (16) and Goodman formula is also related to the stress ratio, the material and the fatigue life. Fig. 15 indicates that, for the materials with the effect of $R$ on fatigue strength described by Eq. (16), Goodman formula usually gives much higher estimated results for $R<0.5$ especially for $R<0$.

\section{Conclusions}

This paper first studies the effect of stress ratio $R$ on fatigue crack growth rate for the region involving that close to and lower than the traditional threshold value of crack propagation $\Delta K_{\mathrm{th}}$, which does not involve the effect of crack closure. It is shown that, the stress intensity factor range $\Delta K$ can be used as a factor to describe the crack growth rate even when it is lower than the value of $\Delta K_{\mathrm{th}}$. The effect of $R$ on the crack growth rate in near-threshold region (below $\Delta K_{\mathrm{th}}$ ) and the crack growth rate in Paris region can be described by the form of $\mathrm{d} a /$ $\mathrm{d} N=C\left(f(R) \Delta K-\Delta K_{\text {th, } 0}^{\prime}\right)^{m}$, with $f(R)=(1-R)^{-\alpha}$, or $f(R)=(1-R)^{-\alpha}$ for $R \geqslant 0$, and $(1-R)^{-1}$ for $R<0$. Then, a formula is deduced to correlate the stress ratio (or mean stress) and the fatigue strength, which shows a good agreement with experimental data for low cycle, high cycle and

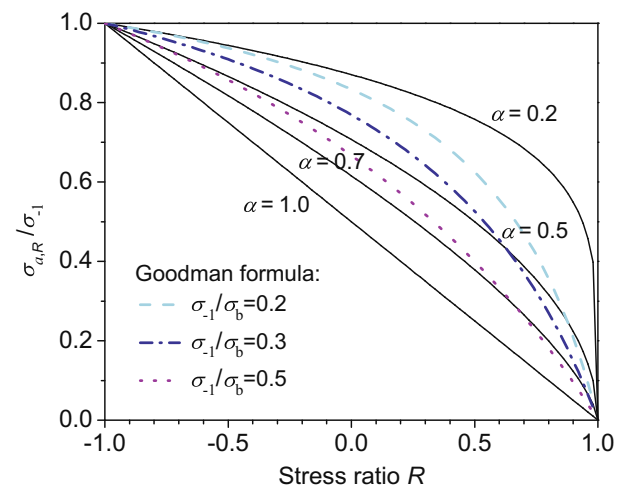

Fig. 14. Comparison of Eq. (14) (solid curves) with Goodman formula.

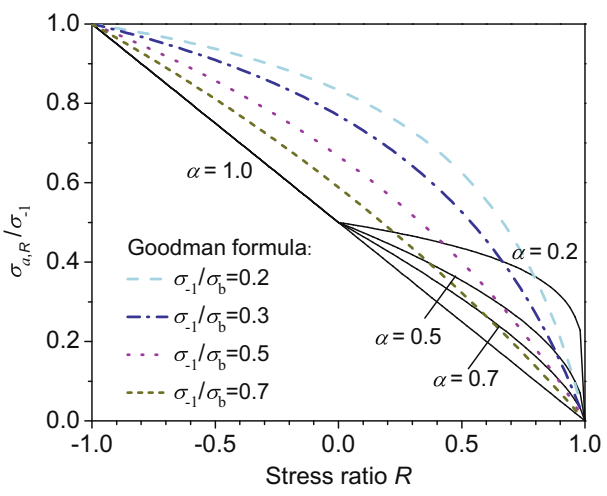

Fig. 15. Comparison of Eq. (16) (solid curves) with Goodman formula.

VHCF regimes in literature. The proposed formula is also compared with Goodman formula, and the difference is discussed.

\section{Acknowledgements}

The project was supported by the National Natural Science Foundation of China (11202210, 11172304 and 11021262) and by the National Basic Research Program of China (2012CB937500).

\section{References}

Baptista, C.A.R.P., Adib, A.M.L., Torres, M.A.S., Pastoukhov, V.A., 2012. Describing fatigue crack growth and load ratio effects in Al 2524 T3 alloy with an enhanced exponential model. Mech. Mater. 51, 66-73.

Budiansky, B., Hutchinson, J.W., 1978. Analysis of closure in fatigue crack growth. ASME J. Appl. Mech. 45, 267-276.

Dinda, S., Kujawski, D., 2004. Correlation and prediction of fatigue crack growth for different R-ratios using $K_{\max }$ and $\Delta K^{+}$parameters. Eng. Fract. Mech. 71, 1779-1790.

Dominguez Almaraz, G.M., 2008. Prediction of very high cycle fatigue failure for high strength steels, based on the inclusion geometrical properties. Mech. Mater. 40, 636-640.

Elber, W., 1970. Fatigue crack closure under cyclic tension. Eng. Fract. Mech. 2, 37-44.

Elber, W., 1971. The significance of fatigue crack closure. In: Damage tolerance in aircraft structures. ASTM STP, vol. 486. American Society for Testing and Materials, Philadelphia (PA, USA), pp. 230-242.

Hong, Y.S., Zhao, A.G., Qian, G.A., Zhou, C.E., 2012. Fatigue strength and crack initiation mechanism of very-high-cycle fatigue for low alloy steels. Metall. Mater. Trans. A 43 (8), 2753-2762.

Hong, Y., Lei, Z., Sun, C., Zhao, A., 2014. Propensities of crack interior initiation and early growth for very-high-cycle fatigue of high strength steels. Int. J. Fatigue 58, 144-151.

Huang, X., Moan, T., 2007. Improved modeling of the effect of R-ratio on crack growth rate. Int. J. Fatigue 29, 591-602.

Ishihara, S., McEvily, A.J., Sato, M., Taniguchi, K., Goshima, T., 2009. The effect of load ratio on fatigue life and crack propagation behavior of an extruded magnesium alloy. Int. J. Fatigue 31, 1788-1794.

Jones, R., Molent, L., Pitt, S., 2008. Similitude and the Paris crack growth law. Int. J. Fatigue 30, 1873-1880.

Kim, J.H., Chau-Dinh, T., Zi, G., Kong, J.S., 2012. The effect of compression stresses, stress level and stress order on fatigue crack growth of multiple site damage. Fatigue Fract. Eng. Mater. Struct. 35, 903-917.

Kondo, Y., Sakae, C., Kubota, M., Kudou, T., 2003. The effect of material hardness and mean stress on the fatigue limit of steels containing small defects. Fatigue Fract. Eng. Mater. Struct. 26, 675-682.

Kujawski, D., 2001a. A fatigue crack driving force parameter with load ratio effects. Int. J. Fatigue 23, S239-S246.

Kujawski, D., 2001b. A new $\left(\Delta K^{+} K_{\max }\right)^{0.5}$ driving force parameter for crack growth in aluminum alloys. Int. J. Fatigue 23, 733-740. 
Lei, Z., Hong, Y., Xie, J., Sun, C., Zhao, A., 2012. Effects of inclusion size and location on very-high-cycle fatigue behavior for high strength steels. Mater. Sci. Eng. A 558, 234-241.

Li, S.L., Yang, Y.F, Xu, R.P., 2007. The influence for average stress effect on P-S-N curves of 45 steel. PTCA (PART: A PHYS. TEST.) 43, 611-613.

Murakami, Y., Nomoto, T., Ueda, T., 1999. Factors influencing the mechanism of superlong fatigue failure in steels. Fatigue Fract. Eng. Mater. Struct. 22 (7), 581-590.

Newman, J., Wu, X.R., Venneri, S.L., Li, C.G., 1994. Small-crack effects in highstrength aluminium alloys. NASA/CAE Cooperative Program, Report No. NASA RP-1309, Langley Research Center, Hapton VA.

Noroozi, A.H., Glinka, G., Lambert, S., 2005. A two parameter driving force for fatigue crack growth analysis. Int. J. Fatigue 27, 1277-1296.

Ostash, O.P., Chepil, R.V., Vira, V.V., 2011. Fatigue crack initiation and propagation at different stress ratio values of uniaxial pulsating loading. Fatigue Fract. Eng. Mater. Struct. 34, 430-437.

Paris, P.C., Erdogan, F., 1963. A critical analysis of crack propagation laws. J. Basic Eng. 85, 528-534.

Paris, P.C., Tada, H., Donald, J.K., 1999. Service load fatigue damage - a historical perspective. Int. J. Fatigue 21, S35-S46.

Pippan, R., Tabernig, B., Gach, E., Riemelmoser, F., 2002. Non-propagation conditions for fatigue cracks and fatigue in the very high-cycle regime. Fatigue Fract. Eng. Mater. Struct. 25, 805-811.

Sadananda, K., Vasudevan, A.K., 2003. Fatigue crack growth mechanisms in steels. Int. J. Fatigue 25, 899-914.

Sakai, T., Sato, Y., Oguma, N., 2002. Characteristic S-N properties of highcarbon-chromium-bearing steel under axial loading in long-life fatigue. Fatigue Fract. Eng. Mater. Struct. 25, 765-773.

Shiozawa, K., Hasegawa, T., Kashiwagi, Y., Lu, L., 2009. Very high cycle fatigue properties of bearing steel under axial loading condition. Int. J. Fatigue 31, 880-888.
Stanzl-Tschegg, S.E., 1999. Fracture mechanisms and fracture mechanics at ultrasonic frequencies. Fatigue Fract. Eng. Mater. Struct. 22, $567-$ 579.

Stanzl-Tschegg, S., SchÖnbauer, B., 2010. Near-threshold fatigue crack propagation and internal cracks in steel. Procedia Eng. 2, 1547-1555.

Sun, C., Xie, J., Zhao, A., Lei, Z., Hong, Y., 2012. A cumulative damage model for fatigue life estimation of high-strength steels in high-cycle and very-high-cycle fatigue regimes. Fatigue Fract. Eng. Mater. Struct. 35, 638-647.

Tanaka, K., Akiniwa, Y., 2002. Fatigue crack propagation behaviour derived from S-N data in very high cycle regime. Fatigue Fract. Eng. Mater. Struct. 25, 775-784.

Takeuchi, E., Furuya, Y., Nagashima, N., Matsuoka, S., 2010. Effect of stress ratio on giga-cycle fatigue properties for Ti-6Al-4V Alloy. Tetsu-toHagané 96, 36-41.

Vasudevan, A.K., Sadanada, K., Louat, N., 1994. A review of crack closure, fatigue crack threshold and related phenomena. Mater. Sci. Eng. A $188,1-22$.

Walker, E.K., 1970. The effect of stress ratio during crack propagation and fatigue for 2024-T3 and 7076-T6 aluminum. In: Effect of environment and complex load history on fatigue life. ASTM STP, vol. 462. American Society for Testing and Materials, Philadelphia, pp. 1-14.

Xiong, Y., Hu, X.X., 2012. The effect of microstructures on fatigue crack growth in Q345 steel welded joint. Fatigue Fract. Eng. Mater. Struct. 35, 500-512.

Zambrano, H.R., Harkegard, G., Staerk, K.F., 2012. Fracture toughness and growth of short and long fatigue cracks in ductile cast iron EN-GJS-400-18-LT. Fatigue Fract. Eng. Mater. Struct. 35, 374 388. 